\title{
TOOTH LOSS AND EDENTULISM AMONG OLDER ADULTS LIVING IN URBAN AREAS IN WEST POMERANIA, NW POLAND
}

\author{
Łukasz Wilczyński, Elżbieta Dembowska \\ Department of Periodontology, Pomeranian Medical University, Szzzecin, Poland
}

\begin{abstract}
INTRODUCTION: At present, older people are a priority group of World Health Organization (WHO) activities in the field of oral health. In Poland, the age group from 65 to 74 years was first included in epidemiological studies of the dental situation in 1998. Loss of teeth affects oral health, quality of life, and possibly the general health of older people.

ОвјестіVEs: To determine the prevalence and factors associated with tooth loss and edentulism among older people in West Pomerania, NW Poland.

MATERIAL AND METHODS: The study included volunteers from a group of 2500 people selected by the Ministry of the Interior and Administration. Information on selected sociodemographic characteristics was obtained based on interviews. Clinical examination provided information on the average number of missing teeth and the number and type of preserved teeth.

RESULTS: The mean number of missing teeth (with SD) in the examined population was 13.1 (8.3). First molars were the most frequently missing teeth in both the maxilla $(65.8 \%)$ and mandible $(81.3 \%)$. There were statistically significant differences in the average number of missing teeth in relation to age, place of residence, level of education, monthly income and source of financing dental treatment. There were three significant risk factors for edentulism: relying solely on the state-funded dental services, $\mathrm{OR}=5.18$ (2.49-10.80), low level of education, $\mathrm{OR}=3.88$ (1.82-8.28), and age, $\mathrm{OR}=1.15$ (1.02-1.29)

ConcLusions: The percentage of completely edentate older adults in West Pomerania, NW Poland remains at a high level. The average number of missing teeth and the percentage of completely edentate older adults depend on economic status and educational level. The proportion of older adults with at least 20 preserved teeth is very low, and therefore the need for prosthetic treatment and masticatory rehabilitation is probably high.
\end{abstract}

KEY WORDS: older adults, tooth loss, edentulism, Poland.

J Stoma 2018; 71, 6: 483-489

DOI: https://doi.org/10.5114/jos.2018.85564

\section{INTRODUCTION}

Literature reports show that partial or total tooth loss is a significant problem in the dental health of older adults. Edentulism causes speech difficulties, problems with appearance, difficulty in chewing, mobility of adjacent teeth [1], temporomandibular disorders (TMD) [2, 3], limited selection of food that can be eaten, weight loss, low self-esteem and reduction of interpersonal contact, drop in the quality of life, and many other problems [4-6].

\section{JOURNAL OF} STOMATOLOGY CZASOPISMO STOMATOLOGICZNE

AdDRESS FOR CORRESPONDENCE: Dr. Łukasz Wilczyński, Department of Periodontology, Pomeranian Medical University, 72 Powstańców Wielkopolskich Str., 70-111 Szczecin, Poland, e-mail: 7wilczynski@gmail.com 
The main causes of tooth loss among adults are tooth decay, periodontal disease and traumas [7]. The risk factors include socioeconomic and cultural factors (e.g. low level of education, low economic status, living in rural areas) [8-10], factors associated with general diseases (e.g. diabetes, asthma, cardiovascular disease) [11, 12], factors related to healthy attitudes and lifestyle (e.g. nicotine consumption, insufficient intake of fruit and vegetables, inadequate hygiene habits) $[13,14]$ and others (e.g. number of dentists per 100,000 inhabitants, low self-esteem). It has been found that tooth loss has an effect on the incidence of some diseases, such as coronary heart disease [15], mortality [16], and electrocardiographic abnormalities [17].

At present, older people are a priority group of World Health Organization (WHO) activities in the field of oral health. In 2007, WHO launched a global review of preventive and curative care and oral health assessment in this age group, focusing on the limitations of available dental care. It was found that up-to-date epidemiological information on oral health, health behaviors and health care makes it possible to create and modify existing preventive and therapeutic programs for older adults [18]. The main goals of the WHO for 2020 , regarding the number of teeth in the age group 65-74 are: to reduce the number of edentulous persons by $\mathrm{X} \%$, increase the number of natural teeth present by $\mathrm{X} \%$, increase the number of individuals with functional dentition (21 or more natural teeth) by $\mathrm{X} \%$ and reduce the number of individuals experiencing difficulties in chewing, swallowing, or speaking/communicating by $\mathrm{X} \%$ [19]. The WHO recommends that epidemiological studies should be repeated at five-year intervals and include well-defined age groups. However, the epidemiological studies carried out in Europe and in the world concerning oral health of older adults are frequently carried out in different age groups and their comparability is inadequate. For example, national epidemiological studies monitoring oral health in Hungary have been conducted since 1985, but the age group 65-74 has only been included in this study since 2000 [20]. The first epidemiological study in Denmark assessing the age group 65-74 years was carried out in 1987, then in 1994 and 2000 [21]. The oral health of the population aged 6574 in Greece was first reported in the second national survey in 2005 [22]. The oral health of older adults in Norway began much earlier. Oral health surveys of Norwegians aged $\geq 60$ years began in 1975, and subsequent studies were conducted in 1985, 1995 and 2002 [23]. In Germany, epidemiological studies have been conducted since 1989 as Deutsche Mundgesundheitsstudie (DMS I), followed by a survey in 1992 (DMS II), 1997 (DMS III) and 2005 (DMS IV) [24]. In Poland, the age group from 65 to 74 years was first included in epidemiological studies in 1998. Current national data are based on studies conducted under the Polish Population Health Program for 2013-2015 [25].

\section{OBJECTIVES}

The aim of the study was to determine the prevalence and factors associated with tooth loss and edentulism among older adults living in West Pomerania, NW Poland.

\section{MATERIAL AND METHODS}

The research was carried out in a group of 294 people aged 65-74 years living in West Pomerania, NW Poland, at the turn of 2014 and 2015 in selected cities. This study is part of a national epidemiological survey of oral health parameters among people from 65 to 74 years old conducted in 2013-2015. The study included the city of Szczecin (population in 2016: 405 413) and the towns of Łobez (10 409) and Police (33 152) [26]. A group of 2500 people was selected by the Ministry of Interior and Administration. Using the data of randomly selected persons received from the Ministry (name, address, residence), we sent letters with information about the possibility of taking part in the study. There was no minimum sample size calculated. The study was performed on the volunteers who were invited to the Clinic of Periodontics of the Pomeranian Medical University in Szczecin for an interview and clinical examination. The exclusion criteria of the study were general contraindications (e.g. endocarditis in the interview) or local contraindications (e.g. acute oral inflammation). The examined individuals were noninstitutionalized. Interviews collected information on sociodemographic characteristics (age, gender, place of residence, level of education, income per family member, and source of funding for dental treatment). A clinical study provided information on the number of missing and preserved teeth. Wisdom teeth were not taken into account in the study. For analytical statistics, the following categorizations were used: age group (65-69 years and 70-74 years); place of residence (city and town); level of education (primary, secondary, bachelor, and master degrees); monthly income $(\leq 800$ PLN [i.e. $\leq 192$ EUR], 801-1500 PLN [192361 EUR], 1501-2500 PLN [361-603 EUR], > 2500 PLN [> 603 EUR]) [27]; sources of financing dental treatment (only those covered by the National Health Fund [NHF], or only private dental offices, or combination of services provided by NHF and private dental offices).

Statistical analysis was carried out using STATA 11 software (License No. 30110532736). Frequencies, means (SD) and line charts were generated. Differences in all the tests were deemed statistically significant at $p<0.05$. A logistic regression model was used to assess the degree of edentulism in relation to various factors. Results were described by an odds ratio (OR) with 95\% confidence and probability intervals. The probability in this model was calculated by Pearson's $\chi^{2}$ test.

Ethical approval to undertake the study was obtained from the Bioethics Commission of the Medical University of Warsaw, Poland (KB/24/2011). 


\section{RESULTS}

From a randomly selected population group aged 65-74 living in West Pomerania, 294 volunteers were included in the study. Only $11.8 \%$ of invited individuals took part in the survey.

TABLE 1. Socio-demographic characteristics of study participants $(n=294)$

\begin{tabular}{|c|c|c|}
\hline Socio-demographic characteristics & No. & $\%$ \\
\hline \multicolumn{3}{|l|}{ Sex } \\
\hline Female & 163 & 55.4 \\
\hline Male & 131 & 44.6 \\
\hline \multicolumn{3}{|l|}{ Age (years) } \\
\hline $65-69$ & 181 & 61.6 \\
\hline $70-74$ & 113 & 38.4 \\
\hline \multicolumn{3}{|l|}{ Place of residence } \\
\hline City & 223 & 75.8 \\
\hline Town & 71 & 24.1 \\
\hline \multicolumn{3}{|l|}{ Level of education } \\
\hline Primary & 52 & 17.7 \\
\hline Secondary & 171 & 58.2 \\
\hline Bachelor & 11 & 3.7 \\
\hline Master & 60 & 20.4 \\
\hline \multicolumn{3}{|l|}{ Monthly income (PLN) } \\
\hline 800 or less & 10 & 3.4 \\
\hline $801-1500$ & 128 & 43.5 \\
\hline $1501-2500$ & 132 & 44.9 \\
\hline$>2500$ & 24 & 8.2 \\
\hline \multicolumn{3}{|l|}{ Sources of dental treatment } \\
\hline National Health Fund (NHF) & 73 & 24.8 \\
\hline Private dental offices & 97 & 33.0 \\
\hline NHF and private dental offices & 124 & 42.2 \\
\hline
\end{tabular}

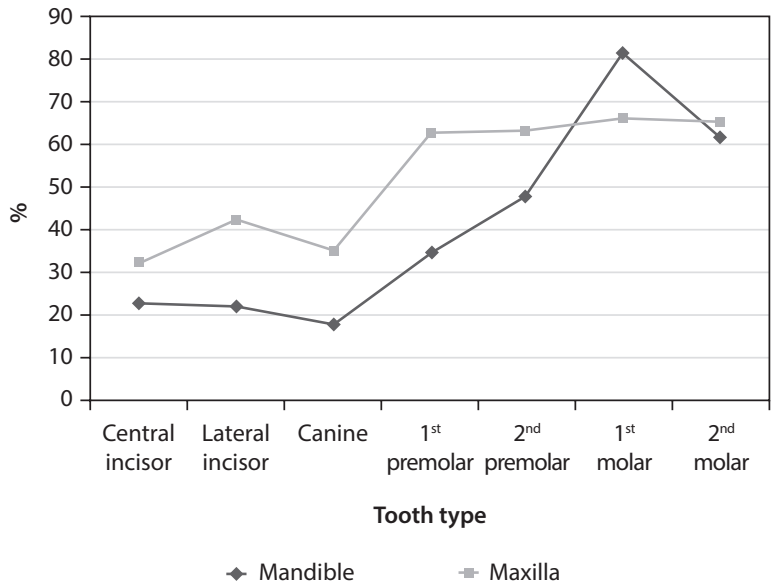

FIGURE 1. Pattern of tooth loss among study participants $(n=291)$
As shown in Table 1, 163 women (55.4\%) and 131 men $(44.6 \%)$ were included in the study. Two hundred and twenty-three respondents $(75.8 \%)$ were city dwellers. The population was divided into two age categories, with $61.6 \%(n=181)$ aged $65-69$ years and the remaining $38.4 \%(n=113)$ aged $70-74$ years. More than $17 \%(n=52$; $17.7 \%)$ had at most primary education, $58.2 \%(n=171)$ secondary education, and $20.4 \%(n=60)$ a master's degree. Only 24 people $(8.2 \%)$ reported income above 2500 PLN per month. Among the participants, $24.8 \%(n=73)$ used only dental services covered by the National Health Fund and $33 \%(n=97)$ used only private dental services.

First molars were the most frequently missing teeth in both the maxilla (65.8\%) and mandible (81.3\%). The least commonly missing teeth in the maxilla were the incisor $(32.6 \%)$ and canine $(35.1 \%)$, and in the mandible the canine (18.2\%) and lateral incisor (22.1\%) (Figure 1).

As shown in Table 2, the mean number of missing teeth in the examined population was $13.1(\mathrm{SD}=8.3)$.

TABLE 2. Relationship between socio-demographic characteristics and the number of missing teeth among study participants $(n=294)$

\begin{tabular}{|c|c|c|c|}
\hline $\begin{array}{l}\text { Socio-demographic } \\
\text { characteristics }\end{array}$ & No. & $\begin{array}{l}\text { Number of } \\
\text { missing teeth; } \\
\text { mean (SD) }\end{array}$ & $p$-value \\
\hline Total & 294 & $13.1(8.26)$ & \\
\hline \multicolumn{4}{|l|}{ Sex } \\
\hline Female & 163 & $13.4(8.5)$ & \multirow[t]{2}{*}{0.62} \\
\hline Male & 131 & $12.76(7.9)$ & \\
\hline \multicolumn{4}{|l|}{ Age (years) } \\
\hline $65-69$ & 181 & $11.8(7.9)$ & \multirow[t]{2}{*}{0.001} \\
\hline $70-74$ & 113 & $15.1(8.3)$ & \\
\hline \multicolumn{4}{|l|}{ Place of residence } \\
\hline City & 223 & $12.6(8.2)$ & \multirow[t]{2}{*}{$<0.05$} \\
\hline Town & 71 & $14.7(8.2)$ & \\
\hline \multicolumn{4}{|l|}{ Level of education } \\
\hline Primary & 52 & $18.5(8.1)$ & \multirow[t]{4}{*}{$<0.0001$} \\
\hline Secondary & 171 & 13.1(7.9) & \\
\hline Bachelor & 11 & $9.5(8.9)$ & \\
\hline Master & 60 & $9(6.7)$ & \\
\hline \multicolumn{4}{|l|}{ Monthly income (PLN) } \\
\hline 800 or less & 10 & $12.8(9.3)$ & \multirow[t]{4}{*}{0.003} \\
\hline $801-1500$ & 128 & $14.9(7.9)$ & \\
\hline $1501-2500$ & 132 & $12.1(8.3)$ & \\
\hline$>2500$ & 24 & $9.1(7.3)$ & \\
\hline \multicolumn{4}{|l|}{ Sources of dental treatment } \\
\hline National Health Fund & 73 & $18.1(8.3)$ & \multirow[t]{3}{*}{$<0.0001$} \\
\hline Private dental offices & 97 & $9.7(6.5)$ & \\
\hline NHF and private dental offices & 124 & $12.7(8.1)$ & \\
\hline
\end{tabular}


It was significantly higher among those aged 70-74 compared to those aged $65-69,15.1(\mathrm{SD}=8.3)$ vs. 11.8 $(\mathrm{SD}=7.9)(p=0.01)$. The average number of missing teeth correlated inversely with the level of education. The largest average number of missing teeth was found among subjects with only primary education $18.5(\mathrm{SD}=8.1)$ and the smallest in the study group with a master's degree $9.0(\mathrm{SD}=6.7)(p<0.0001)$. The lowest average number of missing teeth, 9.1 ( $\mathrm{SD}=7.3$ ), was found among the highest-income patients, which was statistically significant when compared to the other study groups $(p=0.003)$. The individuals using only the services of private dental offices had only half the number of missing teeth compared to those relying only on services provided by the NHF, $9.7(\mathrm{SD}=6.5)$ vs. $18.1(\mathrm{SD}=8.3)(p<0.0001)$.

Table 3 shows that the highest number of edentate people was found in the 70-74 age group ( $n=18 ; 15.9 \%)$ compared to the $65-69$ group $(n=17 ; 9.4 \%)$. It was observed that subjects aged 65-69 years were more likely to have $\geq 20$ preserved teeth $(n=75 ; 41.4 \%)$ compared to those in the $70-74$ age group $(n=30 ; 26.5 \%)(p=0.02)$. The highest percentage of edentate people was recorded in the group with only primary education $(n=14$; $26.9 \%)$. Total edentulism was observed in only 2 people with master's education (3.3\%). Those with a master's degree had $\geq 20$ teeth more often than those with a bachelor degree $(63.6 \%$ vs. $53.3 \%)(p<0.0001)$.

As shown in Table 3, none of the respondents with a monthly income $>2500$ PLN was completely edentate, and only 2 persons in this group $(8.3 \%)$ had just $1-6$ teeth $(p=0.01)$. Only 2 persons using exclusively private dental services $(2.1 \%)$ were completely edentate, compared to 20 people using only public sector NHF services (27.4\%). The NHF group also had the lowest percentage of individuals with at least 20 teeth $(n=11$; $15.2 \%)(p<0.0001)$.

As shown in Table 4, the highest risk of edentulism was associated with relying only on the public dental services $(\mathrm{NHF}) \mathrm{OR}=5.18(2.49-10.80)(p<0.0001)$

TABLE 3. Relationship between socio-demographic characteristics and number of teeth among study participants $(n=294)$

\begin{tabular}{|c|c|c|c|c|c|c|c|}
\hline $\begin{array}{l}\text { Socio-demographic } \\
\text { characteristics }\end{array}$ & $\begin{array}{l}\text { Total } \\
\text { No. }\end{array}$ & $\begin{array}{l}\text { Edentate } \\
\text { No. (\%) }\end{array}$ & $\begin{array}{l}1-6 \text { teeth } \\
\text { No. }(\%)\end{array}$ & $\begin{array}{l}\text { 7-19 teeth } \\
\text { No. }(\%)\end{array}$ & $\begin{array}{l}\geq 20 \text { teeth } \\
\text { No. (\%) }\end{array}$ & $x^{2}$ & $p$-value \\
\hline \multicolumn{8}{|l|}{ Sex } \\
\hline Female & 163 & $22(13.5)$ & $13(8.0)$ & $69(42.3)$ & $59(36.2)$ & \multirow[t]{2}{*}{1.46} & \multirow[t]{2}{*}{0.69} \\
\hline Male & 131 & $13(9.9)$ & $9(6.9)$ & $63(48.1)$ & $46(35.1)$ & & \\
\hline \multicolumn{8}{|l|}{ Age (years) } \\
\hline $65-69$ & 181 & $17(9.4)$ & $10(5.5)$ & $79(43.6)$ & $75(41.4)$ & \multirow[t]{2}{*}{9.39} & \multirow[t]{2}{*}{0.02} \\
\hline $70-74$ & 113 & $18(15.9)$ & $12(10.6)$ & $53(46.9)$ & $30(26.5)$ & & \\
\hline \multicolumn{8}{|l|}{ Place of residence } \\
\hline City & 223 & $25(11.2)$ & $16(7.2)$ & $97(43.5)$ & $85(38.1)$ & \multirow[t]{2}{*}{2.39} & \multirow[t]{2}{*}{0.49} \\
\hline Town & 71 & $10(14.1)$ & $6(8.4)$ & $35(49.3)$ & $20(28.2)$ & & \\
\hline \multicolumn{8}{|l|}{ Level of education } \\
\hline Primary & 52 & $14(26.9)$ & $8(15.4)$ & $22(42.3)$ & $8(15.4)$ & \multirow[t]{4}{*}{36.42} & \multirow[t]{4}{*}{$<0.0001$} \\
\hline Secondary & 171 & $19(11.1)$ & $11(6.4)$ & $83(48.5)$ & $58(33.9)$ & & \\
\hline Bachelor & 11 & $0(0)$ & $1(9.1)$ & $3(27.3)$ & $7(63.6)$ & & \\
\hline Master & 60 & $2(3.3)$ & $2(3.3)$ & $24(40.0)$ & $32(53.3)$ & & \\
\hline \multicolumn{8}{|l|}{ Monthly income (PLN) } \\
\hline 800 or less & 10 & $1(10.0)$ & $2(20.0)$ & $3(30.0)$ & $4(40.0)$ & \multirow[t]{4}{*}{20.89} & \multirow[t]{4}{*}{0.01} \\
\hline $801-1500$ & 128 & $18(14.1)$ & $12(9.4)$ & $66(51.6)$ & $32(25.0)$ & & \\
\hline $1501-2500$ & 132 & $16(12.1)$ & $6(4.5)$ & $56(42.4)$ & $54(40.9)$ & & \\
\hline$>2500$ & 24 & $0(0)$ & $2(8.3)$ & $7(29.2)$ & $15(62.5)$ & & \\
\hline \multicolumn{8}{|l|}{ Sources of dental treatment } \\
\hline National Health Fund (NHF) & 73 & $20(27.4)$ & $9(12.3)$ & $33(45.2)$ & $11(15.2)$ & \multirow[t]{4}{*}{41.61} & \multirow[t]{4}{*}{$<0.0001$} \\
\hline Private dental offices & 97 & $2(2.1)$ & $3(3.1)$ & $44(45.4)$ & $48(49.5)$ & & \\
\hline NHF and private dental offices & 124 & $13(10.5)$ & $10(8.1)$ & $55(44.3)$ & $46(37.1)$ & & \\
\hline Total & 294 & $35(11.9)$ & $22(7.5)$ & $132(44.9)$ & $105(35.7)$ & & \\
\hline
\end{tabular}


followed by low education, $\mathrm{OR}=3.88(1.82-8.28)$ $(p<0.0001)$, and age, $\mathrm{OR}=1.15(1.02-1.29)(p=0.02)$. At the same time, the strongest preventive factor against edentulism was the use of the private dental services, $\mathrm{OR}=0.10(0.02-0.45)(p=0.002)$, then master's degree, $\mathrm{OR}=0.21(0.05-0.90)(p=0.03)$, and monthly income in excess of $2500 \mathrm{PLN}, \mathrm{OR}=0.28(0.01-1.09)$ $(p=0.06)$.

\section{DISCUSSION}

According to demographic predictions, the number of people aged 65 years and more on a global scale will reach one billion in 2030 [28]. Taking into account demographic predictions, proper care for the elderly, including in the field of dental treatment, is particularly important. One of the main problems of dental aging is loss of teeth and associated complications. The key issue is knowledge about oral health of the elderly. The health objectives set by the WHO for 2020 in the 65-74 age group are to reduce the proportion of people with edentulism, to increase the number of present natural teeth and to increase the number of individuals with functional dentition (21 or more natural teeth) [19]. In Poland, epidemiological research on elderly people in urban areas was conducted in 1998, 2002, 2009 and 2013-2015 [25, 29]. In our research, the mean number of preserved teeth was 14.9 and was higher compared with Wrocław (14.0), Warsaw (13.8), Białystok (13.4), Toruń (12.6) [30] and the last national study (13.7) [25]. One optimistic observation of this group in West Pomerania is a decrease in the percentage of edentulism. In 2002, the percentage of completely edentate older adults in West Pomerania was $46.2 \%$ [29], which then dropped to $17.3 \%$ in 2010 , and $11.9 \%$ in 2013-2014 (own research). Over the past 13 years the percentage of completely edentate older adults in the West Pomeranian Region has decreased fourfold. Considering the low reportability for epidemiological studies, these positive observations ought to be interpreted carefully. The percentage of edentate elderly people in West Pomerania was lower than in Wrocław (12.9\%) [30] and Białystok (12.5\%) [31]. In Poland, nationwide epidemiological studies in 2013-2015 showed that $28.9 \%$ of older adults were completely edentate, compared to the $43.9 \%$ in $2009,41.6 \%$ in 2002 , and $34.7 \%$ in 1998 [25, 29].

Epidemiological studies show a higher average number of missing teeth and higher incidence of edentulism among those with a low social status, low income, and lower education $[32,33]$. In our research conducted in West Pomerania, we found 3 risk factors and 3 protective factors related to the occurrence of edentulism in older people. The risk factors were strongly associated with the socioeconomic status, such as reliance only on services provided by the National Health Fund (NHF), low level of education, and age. The aforementioned re-
TABLE 4. Relationship between edentulism and sociodemographic factors

\begin{tabular}{|l|c|c|c|}
\hline Socio-demographic factors & OR & $\begin{array}{c}\text { Edentulism } \\
95 \% \text { Cl }\end{array}$ & p-value \\
\hline Age & 1.15 & $1.02-1.29$ & 0.02 \\
\hline Male sex & 0.71 & $0.34-1.46$ & 0.4 \\
\hline City dweller & 0.77 & $0.35-1.69$ & 0.5 \\
\hline Primary education & 3.88 & $1.82-8.28$ & $<0.0001$ \\
\hline Master's education & 0.21 & $0.05-0.90$ & 0.03 \\
\hline Monthly income less than 800 PLN & 0.82 & $0.10-6.65$ & 0.8 \\
\hline Monthly income > 2500 PLN & 0.28 & $0.01-1.09$ & 0.06 \\
\hline $\begin{array}{l}\text { Services covered by the National } \\
\text { Health Fund }\end{array}$ & 5.18 & $2.49-10.80$ & $<0.0001$ \\
\hline Non-refunded private dental offices & 0.10 & $0.02-0.45$ & 0.002 \\
\hline
\end{tabular}

lationships confirm the regularities observed by other researchers. Peltzer et al. published a literature review based on surveys that reported the incidence of edentulism and described the factors for edentulism: age - over 80 years, OR $=7.26(5.74-9.20), 70-79$ years, $\mathrm{OR}=4.78$ (4.01-5.71), 60-69 years, OR $=1.98(1.69$ 2.31 ), rheumatoid arthritis, $\mathrm{OR}=1.23$ (1.06-1.43), asth$\mathrm{ma}, \mathrm{OR}=1.63(1.14-2.33)$, tobacco smoking in the past, $\mathrm{OR}=1.38(1.09-1.74)$, low consumption of fruit and vegetables, $\mathrm{OR}=1.37(1.10-1.72)$, and significantly limited mobility, OR = $1.51(1.11-2.05)$ [34]. In a study by Eustaquio-Raga et al. in Valencia (Spain) the statistically significant risk factors for total edentulism included: male sex, $\mathrm{OR}=1.53$ (1.01-2.34), living in rural areas, $\mathrm{OR}=1.74(1.11-2.72)$, living in a nursing home, $\mathrm{OR}=3.47$ (2.01-6.04), tobacco smoking, OR = 1.33 (0.75-2.35), poor oral hygiene, $\mathrm{OR}=2.60(1.66-4.08)$, and irregular visits to the dentist, $\mathrm{OR}=3.22(1.57$ 6.62) [35]. Gaio et al. indicated five risk factors for edentulism: Caucasian race, OR = 5.9 (2.1-16.6), low socioeconomic status, $\mathrm{OR}=5.6(2.1-15.0)$, nicotine intake, $\mathrm{OR}=3.5(1.7-7.6)$, female sex, $\mathrm{OR}=2.3(1.0-4.9)$, and old age, $\mathrm{OR}=2.2(1.2-4.1)$ [36]. All of these studies confirm that loss of dentition is closely related to socioeconomic status.

The major limitation of the present study was the low $(11.76 \%)$ reportability of the individuals. For comparison, in the study of Health in Pomerania the percentage of reportability of randomly chosen individuals aged 60-69 was $65.2 \%$ for women and $74.3 \%$ for men [37]. Another weakness of the study is the lack of consideration of the rural environment. The present results may be underestimated also due to the fact that some potential participants with a bad oral condition were not able to take part in the survey. For example, physically or mentally disabled persons are prone to have a worse oral condition than healthy ones, but their disability could be a barrier to the par- 
ticipation in such studies. We also assessed only selected factors associated with tooth loss, excluding general medical factors.

The increase in the number of older adults in the coming years should raise the interest of governments in the implementation and financing of the necessary epidemiological studies in this age group. Epidemiological studies conducted in a standardized and comparable manner make it possible to determine the trends in morbidity and prevalence, and to analyze the risk factors for diseases among older adults. Analysis of the results of epidemiological studies also makes it possible to propose an appropriate preventive program for oral health among older people and provides a basis for discussion on the rational spending of public funds for dental treatment, including prosthetic dental deficiencies.

\section{CONCLUSIONS}

The percentage of completely edentate older adults in West Pomerania, NW Poland remains at a high level. The average number of missing teeth and the percentage of completely edentate older adults depend on economic status and educational levels. The proportion of older adults with at least 20 preserved teeth is very low, and therefore the need for prosthetic treatment and masticatory rehabilitation is probably high.

\section{CONFLICT OF INTEREST}

The authors declare no potential conflicts of interest with respect to the research, authorship, and/or publication of this article.

\section{References}

1. Ibiyemi O, Idiga E. Tooth loss among the elders in an inner city area of Ibadan, Nigeria. Gerodontology 2017; 34: 264-271.

2. Abud MC, Santos JF, Cunha VP, et al. TMD and GOHAI indices of Brazilian institutionalised and community-dwelling elderly. Gerodontology 2009; 26: 34-39.

3. Camacho JG, Oltramari-Navarro PV, Navarro Rde L, et al. Signs and symptoms of temporomandibular disorders in the elderly. Codas 2014; 26: 76-80.

4. Kandelman D, Petersen PE, Ueda H. Oral health, general health, and quality of life in older people. Spec Care Dent 2008; 28: 224-236.

5. Jensen PM, Saunders RL, Thierer T, et al. Factors associated with oral health-related quality of life in community-dwelling elderly persons with disabilities. J Am Geriatr Soc 2008; 56: 711-717.

6. Naito M, Yuasa H, Nomura Y, et al. Oral health status and health related quality of life: a systematic review. J Oral Sci 2006; 48: 1-7.

7. Momen-Heravi F, Babic A, Tworoger SS, et al. Periodontal disease, tooth loss and colorectal cancer risk: results from Nurses' Health study. Int J Cancer 2016; 140: 646-652.

8. Hugo FN, Hilgert JB, de Sousa Mda L, et al. Correlates of partial tooth loss and edentulism in the Brazilian elderly. Community Dent Oral Epidemiol 2007; 35: 224-232.

9. Mendes DC, Poswar O, de Oliveira MV, et al. Analysis of socio-demographic and systemic health factors and the normative conditions of oral health care in a population of the Brazilian elderly. Gerodontology 2012; 29: 206-214.

10. Northridge ME, Ue FV, Borrell LN, et al. Tooth loss and dental caries in community-dwelling older adults in northern Manhattan. Gerodontology 2012; 29: 464-473.

11. Felton DA. Edentulism and comorbid factors. J Prosthodont 2009; 18: 88-96.

12. Patel MH, Kumar JV, Moss ME. Diabetes and tooth loss: an analysis of data from the national health and nutrition examination survey, 2003-2004. J Am Dent Assoc 2013; 144: 478-485.

13. Wennström A, Ahlqwist M, Stenman U, et al. Trends in tooth loss in relation to socio-economic status among Swedish women, aged 38 and 50 years: repeated cross-sectional surveys 1968-2004. BMC Oral Health 2013; 13: 63.

14. Dolan TA, Gilbert GH, Duncan RP, et al. Risk indicators of edentulism, partial tooth loss and prosthetic status among black and white middle-aged and older adults. Community Dent Oral Epidemiol 2001; 29: 329-340.

15. Eller JR, Champagne CM, Offenbacher S, et al. Relationship of periodontal disease and tooth loss to prevalence of coronary heart disease. J Periodontol 2004; 75: 782-790.

16. Hamalainen P, Meurman JH, Keskinen M, et al. Relationship between dental health and 10-year mortality in a cohort of community dwelling elderly people. Eur J Oral Sci 2003; 111: 291-296.

17. Takaka Y, Ansai T, Natsunma K, et al. Relationship between tooth loss and electrocardiographic abnormalities in octogenarians. J Dent Res 2001; 80: 1648-1652.

18. Petersen PE, Kandelman D, Arpin S, et al. Global oral health of older people - call for public health action. Community Dent Health 2010; 27: 257-268.

19. Hobdell M, Petersen PE, Clarkson J, et al. Global goals for oral health 2020. Int Dent J 2003; 53: 285-288.

20. Madléna M, Hermann P, Jáhn $M$, et al. Caries prevalence and tooth loss in Hungarian adult population: results of a national survey. BMC Public Health 2008; 8: 364.

21. Petersen PE, Kjoller M, Christensen LB, et al. Changing dentate status of adults, use of dental health services, and achievement of national dental health goals in Denmark by the year 2000 . J Public Health Dent 2004; 64: 127-135.

22. Mamai-Homata E, Polychronopoulou A, Oulis C, et al. Periodontal Diseases in Greek Senior Citizens-Risk Indicators. INTECH Open Access Publisher 2012; 11: 231-252.

23. Holst D. Oral health equality during 30 years in Norway. Community Dent Oral Epidemiol 2008; 36: 326-334.

24. Holtfreter B, Kocher T, Hoffmann T, et al. Prevalence of periodontal disease and treatment demands based on a German dental survey (DMS IV). J Clin Periodontol 2010; 37: 211-219.

25. Konopka T, Dembowska E, Pietruska M, et al. Periodontal status and selected parameters of oral condition of Poles aged 65 to 74 years. Przegl Epidemiol 2015; 69: 643-647.

26. Central Statistical Office in Poland: Population. 2016; 234-236.

27. The National Bank of Poland. Available at: http://www.nbp.pl/ home.aspx?navid=archa\&c=/ascx/tabarch.ascx\&n=a031z140214. Accessed: 19.04.2017. Tab. 031/A/NBP/2014.

28. National Institute on Aging. Rising numbers of the oldest old. In: Why Population Aging Matters: A Global Perspective. [online]. 2007, 10-15. Available at: http://www.nia.nih.gov/publication.

29. Jodkowska E. The condition of dentition status of adults Polish citizens in years 1998-2009. Przegl Epidemiol 2010; 64: 571-576.

30. Konopka T, Zawada Ł, Kobierzycka A, Chrzęszczyk D. Periodontal condition in 35-44 and 65-74 year-old residents from Lower Silesia Region. Dent Med Probl 2015; 52: 447-454.

31. Sulewska M, Pietruski J, Sulima E, et al. Periodontal status of Białystok citizens aged 65-74 years: a pilot study. Dent Med Probl 2017; 54: 173-178.

32. Petersen PE. The World Oral Health Report 2003: continuous improvement of oral health in the $21^{\text {st }}$ century - the approach of the WHO Global Oral Health Programme. Community Dent Oral Epidemiol 2003; 31: 3-24. 
33. Borreani E, Wright D, Scambler S, et al. Minimizing barriers to dental care in older people. BMC Oral Health 2008; 26: 7-8.

34. Peltzer K, Hewlett S, Yawson AE, et al. Prevalence of loss of all teeth (edentulism) and associated factors in older adults in China, Ghana, India, Mexico, Russia and South Africa. Int J Environ Res Public Health 2014; 30: 11308-11324.

35. Eustaquio-Raga MV, Montiel-Company JM, Almerich-Silla JM. Factors associated with edentulousness in an elderly population in Valencia (Spain). Gac Sanit 2012; 27: 123-127.

36. Gaio EJ, Haas AN, Carrard VC, et al. Oral health status in elders from South Brazil: a population-based study. Gerodontology 2012; 29: 214-223

37. Holtfreter B, Schwahn Ch, Biffar R, Kocher T. Epidemiology of periodontal diseases in the study of health in Pomerania. J Clin Periodontol 2009; 36: 114-123. 